PROCEEDINGS OF THE

AMERICAN MATHEMATICAL SOCIETY

Volume 129, Number 8, Page 2503

S 0002-9939(01)06230-X

Article electronically published on March 15, 2001

\title{
ERRATUM TO "ON THE SET OF TOPOLOGICALLY INVARIANT MEANS ON AN ALGEBRA OF CONVOLUTION OPERATORS ON $L^{p}(G)$ "
}

\author{
EDMOND E. GRANIRER
}

(Communicated by Dale E. Alspach)

There is a minor gap in the proof of Proposition 1 on p. 3401 of [1. To mend it one has to do the following changes on p. 3401, row 4 from the top (the first row of the proof of Proposition 1):

1. Delete the word "normal".

2. Insert the following after "(8.7)" and before ")": and use the fact that $G$ contains a compactly generated closed subgroup.

\section{REFERENCES}

[1] Edmond E. Granirer, On the set of topologically invariant means on an algebra of convolution operators on $L^{p}(G)$, Proc. Amer. Math. Soc. 124 (1996), 3399-3406. MR 97a:43004

Department of Mathematics, The University of British Columbia, Vancouver, British Columbia, Canada V6T 1Z2

E-mail address: granirer@math.ubc.ca

Received by the editors December 11, 2000.

1991 Mathematics Subject Classification. Primary 43A22, 42B15, 22D15; Secondary 42A45, 43A07, 44A35, 22D25. 